\title{
Acute renal failure during the pregnancy: a review on pathophysiology, risk factors and management
}

\author{
Abolfazl Abdollahpour $^{(\mathbb{D}}$, Hoda Doustmohammadi² $^{2}$ Leila Sadeghi $^{3}$, Babak Hosseinzadeh Zoroufchi ${ }^{*}$ (D) \\ ${ }^{1}$ Department of Anesthesiology, Kowsar Hospital, Semnan University of Medical Sciences, Semnan, Iran \\ ${ }^{2}$ Department of Anatomy, School of Medicine, Semnan University of Medical Sciences, Semnan, Iran \\ ${ }^{3}$ Center of obstetrics and Gynecology, Shahid Mahallati Hospital, Tabriz, Iran
}

\section{A R T I C L E I N F O}

Article Type:

Review

\section{Article History:}

Received: 9 April 2018

Accepted: 10 July 2018

Published online: 13 August 2018

\section{Keywords:}

Acute renal failure

Pregnancy

Outcomes

Risk factors

\begin{abstract}
A B S T R A C T
Acute renal failure (ARF) is a major medical problem during pregnancy with maternal and fetal outcomes. While the trend of pregnancy-related ARF is on a decline due to the advances in obstetrics care and the legality of abortion among developed countries, this situation remains one of the serious health problems in the developing nations. This review aims to evaluate the current studies with regards to pregnancy related ARF pathophysiology, risk factors and treatment. PubMed, Embase, Scopus and directory of open access journals (DOAJ) databases were searched to obtain the information. Most of the studies in this review were conducted in observational, both prospective and retrospective studies. Results demonstrated a variety of major pregnancy-related ARF causes including obstetric hemorrhage, hypertensive disorders in pregnancy, sepsis, thrombotic microangiopathy and acute fatty liver in pregnancy. Aside from awareness of the pathogenesis of pregnancy-related ARF and its risk factors, understanding the physiological renal adaptation during pregnancy is essential for early detection, diagnosis, and proper management to prevent the pregnancy related complications.
\end{abstract}

Implication for health policy/practice/research/medical education:

Obstetric acute renal failure (ARF) is a serious condition which can occur in different phases of pregnancy. Its materno-fetal outcomes hence remain as a critical pregnancy-related complication in both developed and developing countries.

Please cite this paper as: Abdollahpour A, Doustmohammadi H, Sadeghi L, Hosseinzadeh Zoroufchi B. Acute renal failure during the pregnancy: a review on pathophysiology, risk factors and management. J Renal Inj Prev. 2018;7(4):314-320. DOI: 10.15171 jrip.2018.68.

\section{Introduction}

Maternal mortality has significantly decreased over the last decades. Obstetric acute renal failure (ARF), known as pregnancy-related acute kidney injury, is a rare and potentially life-threatening complication of pregnancy $(1,2)$. The incidence of ARF during pregnancy has diminished in both developed and developing nations (3, 4 ), with the incidence of $2 \%-8 \%$ in developed nations and $4.2 \%-15 \%$ in developing countries. It has been recently reported that the insistence of ARF of pregnancy has reduced due to the prenatal care $(5,6)$. However, this issue is associated with enhanced morbidity and mortality rates (2). Major risk factors for obstetric ARF include chronic hypertensive disease, pre-eclampsia, postpartum hemorrhage, antepartum hemorrhage, sepsis, and other infections (7-9).

Obstetric ARF has a bi-modal distribution, one peak occurring during the seventh and eighth weeks of pregnancy (first trimester) mostly as a result of hyperemesis gravidarum (HG) and a second peak occurring during the 32nd and 36th weeks of pregnancy (10). Common cause of obstetric ARF during the first half is septic abortion $(\mathrm{SAB})$ and abruptio placentae $(\mathrm{ABP})$ or preeclampsia have been introduced as the causes of second half of pregnancy. Obstetric ARF occurs in postpartum period due to hemolytic uremic syndrome (HUS) (6). Moreover, renal cortical necrosis remains a terrible complication of obstetric ARF with highly rate of morbidity and mortality (2).

Management of obstetric ARF requires knowledge of the renal physiologic changes occurring in pregnancy and the relevant diagnoses, both pregnancy-specific and those that may coincidental occur with pregnancy. Ideal medical care of these patients needs a multi-disciplinary approach considering maternal and fetal risks and timely specialist 
involvement. In this review, we aimed to investigate the renal function during pregnancy, obstetric ARF and its pathophysiology, risk factors and management.

\section{Methods and Materials}

For this review, we used a variety of sources including PubMed, Embase, Scopus and directory of open access journals (DOAJ). The publications investigating the occurrence of acute renal failure during the pregnancy were included. The search was conducted using combinations of the following keywords and or their equivalents; Acute renal failure, pregnancy, outcomes, Risk factors.

\section{Physiology of kidney during pregnancy}

Normal pregnancy accompanies a number of physical and psychological changes. The urinary tract is a system that demonstrates remarkable alterations in both anatomy and physiology. Understanding these changes is crucial in evaluating renal diseases in pregnant women. Initially, the size of the kidney increases by $1.0-1.5 \mathrm{~cm}$ in length (11). Primarily, the change is in the collecting system (11). This is the result of tissue hypertrophy (12), renal vascular and interstitial space expansion (13). The renal pelvis, calyces and ureters are also dilated, expanding to the pelvic brim (11). It is postulated that nearly $90 \%$ of normal pregnant women develop physiological hydronephrosis (12), with more pronounced dilatation noted in right kidney (12). This is probably due to the dextrorotation of the uterus and dilatation of right ovarian venous plexus (11), as evident from ultrasonography (12). In addition, the gravid uterus causes partial extrinsic mechanical obstruction of the urinary tract (12). The progesterone hormone directly exerts its effect on smooth muscle relaxation (12-14), while prostaglandin E2 inhibits ureteric tone and peristalsis (13). All of these changes lead to urinary stasis, increased risk of bacterial overgrowth, and urinary tract infections (11). These anatomic findings persist up to 12 -week postpartum before returning to pre-pregnancy state $(11,14)$. Regarding kidney hemodynamics, renal plasma flow elevates by $5 \%-70 \%$ (13), and can reach up to $85 \%$ in the second trimester (13). After conception, the glomerular filtration rate (GFR) increases continuously and the increment can be up to $25 \%$ at the 4 th week of gestation (12). It reaches a peak at $65 \%$ increase from the baseline at around the 13th week of gestation (13). This consequently leads to hyperfiltration state, providing other physiological changes such as an increase in uric acid clearance, increased excretion of calcium, glycosuria, increased filtration of amino acids, and increased creatinine $(\mathrm{Cr})$ clearance. In addition to a diminished blood urea nitrogen (BUN) level (15), serum Cr considerably falls to a pregnancy range of $0.4-0.8 \mathrm{mg} / \mathrm{dL}$ (12). Hence, a serum Cr level of $\geq 1.0 \mathrm{mg} /$ $\mathrm{dL}$, though within a normal limit in general population signifies renal impairment in the pregnant population and prompts further investigations (13).
Obstetric ARF; incidence and definition

The incidence of obstetric ARF is a common issue in the developing countries (16). Recently, this incidence reported to be reduced because of decreased septic abortion and improved caring services $(5,13,16,17)$. It has been recorded that the occurrence of obstetric ARF has diminished to 1 in 18000 in developed countries since the 1960s (4). Socioeconomic factors contributing to obstetric ARF in the underdeveloped countries are mainly due to poverty, poor obstetrics care, lack of proper healthcare facilities and awareness of the condition, delayed referral process, multi-parity, and the increasing population proportion $(12,15,18)$.

Pregnancy results in important alterations in acidbase, electrolyte, and renal function due to pregnancyassociated physiologic changes in renal and systemic hemodynamics (19). According to the introduction by Kidney Disease; Improving Global Outcomes (KDIGO), acute kidney injury is defined if an enhance in serum $\mathrm{Cr}$ more than $26.5 \mu \mathrm{mol} / \mathrm{L}$ within 48 hours (20). Nevertheless, during gestational time, increased renal blood flow directed to glomerular hyperfiltration accompanying by a lower serum $\mathrm{Cr}$ value. Therefore, the normal values in the non-pregnant situation can define as an abnormal value in pregnancy (21). Obstetric ARF was defined if the level of serum $\mathrm{Cr}$ was more than $70.72 \mathrm{umol} / \mathrm{L}$ in cases without chronic renal failure (19). Chronic kidney disease (CKD) was defined as presence of any indicators for renal disease containing dropped kidney function (GFR $<60$ $\mathrm{mL} / \mathrm{min} / 1.73 \mathrm{~m}^{2}$ ), proteinuria, hematuria and/or kidney pathological damage for at least three months (22). In chronic renal failure patients, ARF was characterized as a $50 \%$ increase in the level of serum Cr versus baseline (20). Obstetric ARF bears a high risk of bilateral renal cortical necrosis and consequently of chronic renal failure. Renal cortical necrosis is an unusual entity and estimated for only $2 \%$ of all patients with obstetric ARF (6).

From early pregnancy, augmented kidney blood flow directs to an increase in the filtration rate by more than $50 \%$ (21). Alterations may persist for up to twelve weeks postpartum. Normal plasma Cr falls to $44 \mathrm{umol} / \mathrm{L}$ and any value above $70.72 \mathrm{umol} / \mathrm{L}$ should be considered abnormal $(19,21)$. Under-recognition of ARF and a delayed diagnosis might lead to underestimating the frequency of ARF during pregnancy and puerperium. In a previous investigation on a Chinese population, $70.72 \mathrm{umol} / \mathrm{L}$ was applied as the cut-off value for abnormalities in pregnant women. Seventy-five cases (2.51\%) of ARF were identified in 2988 adult pregnant women (23).

\section{Risk factors of obstetric ARF}

\section{Severe hyperemesis gravidarum and obstetric ARF}

Severe hyperemesis gravidarum is one of the rare and potentially devastating complication during the pregnancy. It is known that pregnant women commonly exhibit mild 
to moderate nausea and vomiting until 16 weeks, and these symptoms are frequently self-limited. According to the literature, about $0.5 \%$ to $1 \%$ of all pregnancies present with severe vomiting and nausea followed by the reduced body weight by more than $10 \%(24,25)$. The multifactorial features are involved in the pathogenesis of hyperemesis gravidarum and may be related with high levels of hormone of serum such as progesterone, estriol, thyroxine, human chorionic gonadotropin (HCG), leptin and ghrelin in pregnancy $(26,27)$. Hyperemesis gravidarum may be associated with many potential complications such as dehydration, hypotension, malnutrition, ketosis, alkalosis from loss of hydrochloric acid, hypokalemia, hepatic and renal dysfunctions and Wernicke encephalopathy during pregnancy. These complications may be fatal to both fetus and mother $(28,29)$. In addition, women with hyperemesis gravidarum are vulnerable to higher levels of free T4 and lower TSH of serum (7). As well, it has been suggested that women with hyperemesis gravidarum are at the higher risk of developing related disorders of placenta including preeclampsia, placental abruption and small for gestational age (SGA) (30). The women with severe hyperemesis gravidarum are at risk for obstetric ARF due to the dehydration and severe intravascular volume depletion in association with severe nausea and vomiting (31). The Obstetric ARF arising from severe hyperemesis gravidarum is unusual but have been investigated in different case reports.

In a study by Hill et al, a 21-year-old woman at 15 weeks' gestation refereeing to the emergency department with severe hyperemesis gravidarum associated with obstetric ARF was recorded. Her BUN and initial serum Cr were $171 \mathrm{mg} / \mathrm{dL}$ and $10.7 \mathrm{mg} / \mathrm{dL}$, respectively. To manage obstetric ARF, daily hemodialysis was performed for 5 days. The function of the kidney returned to a normal state following the hemodialysis (32). In a similar study, Shim et al recorded a 20 -year-old woman who presented to the emergency department with severe hyperemesis gravidarum associated with a loss of kidney function at 25 weeks' gestation. Her initial serum $\mathrm{Cr}$ and BUN were 5.0 and $45.9 \mathrm{mg} / \mathrm{dL}$, respectively. The patient underwent hemodialysis for three days and achieved a subsequent recovery of renal function. Presence of case indicates that clinicians should be aware of the possibility of acute kidney injury associated with severe hyperemesis gravidarum although it is rare (33). Thus, to control the subsequent disorders, the severe vomiting and nausea should be considered during pregnancy.

\section{Septic abortion and obstetric ARF}

Occurrence obstetric ARF is traditionally described in the early trimester of pregnancy due to septic abortion (34). Over the last few decades, the etiology of obstetric ARF has changed. In the late 1970s, septic abortion has been introduced as the main cause of obstetric ARF
(35). Patel et al (36), (41.7\%), Kilari et al (37), (39.02\%) and Goplani et al (6) (61.42\%) showed that septicemia was the commonest cause of obstetric ARF. In a study by Altıntepe et al in the central Anatolia, a declination of obstetric ARF was in relation to the reduction in septic abortion by $30 \%$ in the last 20 years (38). This reduction was due to the improved socioeconomic situation, early detection of obstetric ARF and management of obstetricrelated complications. The proportion of ARF secondary to septic abortion has decreased from $33.3 \%$ to $1.8 \%$ over the past 20 years (39). However, according to some studies, septic abortion has been reported as the most common reason for obstetric ARF. Najar et al showed that septic abortion was accounted for $50 \%$ of patients with obstetric ARF (75\% occurred in the first trimester and $25 \%$ in the second trimester) (17). A study carried out by Rahman et al in Bangladesh, illustrated similar results that septic abortion was the main cause of obstetric ARF (16). In addition to absent or irregular antenatal care, home births (36) and low education (16), the majority of cases with obstetric ARF were from rural areas where abortions were done by local village practitioners or traditional birth attendants (40) or untrained midwives (17). Additionally, Utaş et al investigated 149 patients who had suffered obstetric ARF during septic abortion. The important cause of obstetric ARF was bacterial shock (85.2\%). In this study combating shock, stimulating diuresis, blood transfusions, and early cleansing of the uterine cavity were performed to management and treatment of this disease in the prophylaxis. They reported that $69.1 \%$ of the cases recovered, but $39.1 \%$ died. Follow-up investigations in 79 patients revealed that obstetric ARF was later complicated by chronic pyelonephritis (39). They reported that $69.1 \%$ of the cases recovered, but $39.1 \%$ died. Followup investigations in 79 patients revealed that obstetric ARF was later complicated by chronic pyelonephritis (39). Munib et al (34) noticed that pregnancy induced hypertension was the commonest cause (54.54\%) of obstetric acute kidney injury in their study. Their study also had 9 patients with hypertension when referred for dialysis. Whether the hypertension was pregnancy induced or a complication of renal failure was unclear.

\section{Abruptio placenta and obstetric ARF}

Abruptio placenta is known as the premature separation of normally implanted placenta, either partially or completely. Both are the main causes of maternal morbidity and perinatal mortality globally and it is of serious concern in the developing countries $(41,42)$. Dambal et al investigated the obstetric ARF in a three-year study at a medical college hospital in north Karnataka, India. Their results showed that the commonest resound of obstetric ARF was abruptio placenta (9 cases) (43). Aishwarya et al reported a 32 -year old woman at 33rd weeks of gestation with mild anemia and preeclampsia. 
She was treated with antihypertensive drugs and kept under observation. Four hours after admission, she had increased abdominal pain and examination revealed scar tenderness. Although the emergency segment Caesarean section was performed in view of threatened scar rupture, the intra-operative finding was abruptio placentae. Three hours after operation, obstetric ARF was developed. The underlying causes for obstetric ARF were detected mild abruptio placenta, preeclampsia and pre-existed anemia (44).

\section{Hypertensive disorders of pregnancy and obstetric ARF} The hypertensive disorders of pregnancy (HDPs), chronic (or pre-existing) hypertension, gestational hypertension and, especially, pre-eclampsia, remain leading causes of maternal and perinatal morbidity and mortality as well as identifying individuals at increased risk for obstetric ARF (45). Hypertensive disorders of pregnancy are reported as common cause of obstetric ARF during the first half of pregnancy (6). Hypertension during pregnancy has been known as a systolic blood pressure (BP) $\geq 140$ $\mathrm{mm} \mathrm{Hg}$ and/or diastolic BP $\geq 90 \mathrm{~mm} \mathrm{Hg}$ (45). Severe hypertension is defined as systolic BP $\geq 160 \mathrm{~mm} \mathrm{Hg}$ (instead of $170 \mathrm{~mm} \mathrm{Hg}$ ) as that level of systolic BP reflects stroke risk (45-47). Although the rate of hypertensive disorders of pregnancy has not changed substantially in recent years (48), there have been significant changes in the controlling of hypertension during pregnancy (49). In particular, guidelines promoting fluid restriction to prevent pulmonary edema or changes in drugs for control of hypertension in combination with changes in pain management may have had a secondary impact on increasing the obstetric ARF through hypovolaemia, renal hypoperfusion, or nephrotoxicity (49-51). Pre-eclampsia was characterized as a presence of two signs; proteinuria and hypertension after twenty weeks of gestation. As well, eclampsia was known as existence of pre-eclampsia and seizures. HELLP syndrome (characterized by hemolysis, elevated liver enzymes, and low platelet count) has been characterized by hemolysis, elevated liver enzymes, and low platelet count in existence of pre-eclampsia (52). HUS was identified as existence of hemolytic anemia, ARF and thrombocytopenia (53). Numerous studies reported this condition as the most common cause of obstetric ARF $(11,54,55)$. The maternal mortality rate was reported between $6 \%$ and $30 \%$ (56). Predilection of hypertensive disorders of pregnancy peaks at two settings; young primigravida and older multiparous women. Spectrum of hypertension disorders of pregnancy can be classified into five categories; chronic hypertension, preeclampsia, eclampsia, gestational hypertension and preeclampsia superimposed on chronic hypertension. Among these entities, studies revealed that preeclampsia and eclampsia accounted for most obstetric ARF cases. Hypertensive conditions in pregnancy occur in about
$7 \%$ of all pregnancies and it remains the leading cause of maternal-fetal mortality. It is also associated with intrauterine growth restriction and small for gestational age babies (11). Preeclampsia is defined as the new onset of persistent hypertension (systolic BP $\geq 140 \mathrm{~mm} \mathrm{Hg}$ or diastolic $\mathrm{BP} \geq 90 \mathrm{~mm} \mathrm{Hg}$ ) accompanied with proteinuria > $300 \mathrm{mg} / \mathrm{d}$, after the 20th week of gestation (57). Eclampsia is defined as preeclampsia with the presence of seizure (5). Etiologies of preeclampsia are said to be multi-factorial. Maternal risk factors can be grouped into three major factors: obstetric factors, co-morbid factors and genetic factors.

\section{Postpartum hemorrhage and obstetric ARF}

Postpartum hemorrhage is known as bleeding more than $500 \mathrm{~mL}$ within the first 24 hours following delivery (58). Occurring obstetric ARF in postpartum period is a specific entity and may be considered as a form of HUS (6). An alternative hypothesis was related to hypertensive disorders of pregnancy, which represents the most important risk factor for obstetric ARF (9).

\section{Management and treatment of obstetric ARF}

Management of obstetric ARF requires a lot of resources and involves a multidisciplinary team of medical specialists, as well as early detection and prompt intervention. Provision of care should be executed early, timely, and correctly. Model of obstetric ARF care should be targeted to the following aspects; hemodynamic stabilization, maternal and fetal monitoring, and treatment of underlying conditions. Hemodynamic status can be optimized by adequate fluid replacement to correct volume deficit, electrolyte correction, control of bleeding, and blood transfusion when is necessary (12). BP should also be controlled in hypertensive pregnant women (13). These could minimize the progression of further kidney damage. In certain situations, renal replacement therapy of any modalities may be initiated. Medical indication for dialysis remains the same as in the nonpregnant populations $(12,13,15)$. Monitoring of maternal $\mathrm{BP}$, renal function tests, and urine protein examination (14), are necessary and should be performed frequently to early detect any abnormalities. Fetal monitoring can be done by several methods. Evaluation of the fetus at the gestational age of less than 25 weeks is limited to Doppler auscultation. Other more sensitive methods that can be deployed at the later age of gestation comprise of fetal movement assessment, contraction stress test, and biophysical profile (15). Regular fetal monitoring is helpful in the early detection of fetal distress. Importantly, the underlying diseases should always be identified and treated. For instance, the proper use of antibiotics according to the culture and sensitivity is essential in cases of infection. Fluid and electrolytes repletion is warranted in those presented with hyperemesis gravidarum. Blood 
transfusion should be rendered to those with massive obstetric hemorrhage. Management of preeclampsia is targeted to BP control, prevention of seizure, and timely delivery (12). In TMA, treatment with plasmapheresis is proper and efficient to increase maternal survival (13). In acute fatty liver of pregnancy (AFLP), correction of coagulopathy with blood components, hypoglycemic prevention with adequate glucose administration, and hepatic encephalopathy treatment with low-protein diet and oral lactulose are all essential to stabilize the mother (13).

\section{Conclusion}

Obstetric ARF is a serious condition which can occur in different phases of pregnancy. Its materno-fetal outcomes hence remain as a critical pregnancy related complication in both developed and developing countries. Studies had been performed to evaluate the etiologies of obstetric ARF and results had been extensively varied. The most major causes of obstetric ARF in the early trimester are hyperemesis gravidarum and septic abortion. During the late trimester, common causes of obstetric ARF include hypertensive disorders in pregnancy. In conclusion, prevention is the most effective technique for dealing with this life-threatening situation.

\section{Author's contribution}

$\mathrm{AA}, \mathrm{HD}$ and $\mathrm{BHZ}$ searched the data and prepared the draft of the manuscript. BHZ and LS edited and finalized the manuscript. All authors read and signed the final manuscript.

\section{Conflicts of interest}

The authors declare no competing interests.

\section{Ethical considerations}

Ethical issues (including plagiarism, data fabrication, double publication) have been completely observed by the authors.

\section{Funding/Support}

None.

\section{References}

1. Acharya A, Santos J, Linde B, Anis K. Acute kidney injury in pregnancy-current status. Adv Chronic Kidney Dis. 2013;20:215-22. doi: 10.1053/j.ackd.2013.02.002.

2. Prakash J, Kumar H, Sinha D, Kedalaya P, Pandey L, Srivastava $\mathrm{P}$, et al. Acute renal failure in pregnancy in a developing country: twenty years of experience. Ren Fail. 2006;28:309-13. doi: 10.1080/08860220600583658.

3. Pertuiset N, Ganeval D, Grünfeld J-P. Acute renal failure in pregnancy. The Kidney in Pregnancy. Springer; 1986. p. 165-84.

4. Stratta P, Besso L, Canavese C, Grill A, Todros T, Benedetto C, et al. Is pregnancy-related acute renal failure a disappearing clinical entity? Ren Fail. 1996;18:575-84. doi: $\quad 10.3109 / 08860229609047680$.

5. Gammill HS, Jeyabalan A. Acute renal failure in pregnancy. Crit Care Med. 2005;33:S372-S84. doi: 10.1097/01.CCM.0000183155.46886.C6.

6. Goplani K, Shah P, Gera D, Gumber M, Dabhi M, Feroz A, et al. Pregnancy-related acute renal failure: A singlecenter experience. Indian J Nephrol. 2008;18:17. doi: 10.4103/0971-4065.41283.

7. Caffrey TJ. Transient hyperthyroidism of hyperemesis gravidarum: A sheep in wolfs clothing. J Am Board Fam Pract. 2000;13:35-8.

8. Turney J, Marshall D, Brownjohn A, Ellis C, Parsons F. The evolution of acute renal failure, 1956-1988. Q J Med. 1990;74(1):83-104.

9. Gurrieri C, Garovic VD, Gullo A, Bojanić K, Sprung J, Narr BJ, et al. Kidney injury during pregnancy: associated comorbid conditions and outcomes. A Arch Gynecol Obstet. 2012;286:567-73. doi: 10.1007/s00404-012-23235.

10. Chugh K. Etiopathogenesis of acute renal failure in the tropics. Ann Natl Acad Med Sci. 1987;23:88-99.

11. Sahay M. Acute kidney injury in pregnancy. Basic nephrology and acute kidney injury: Open access peerreviewed Edited volume. InTech; 2012.

12. Khanal N, Ahmed E, Akhtar F. Epidemiology, causes and outcome of obstetric acute kidney injury. Novel Insights on Chronic Kidney Disease, Acute Kidney Injury and Polycystic Kidney Disease. InTech; 2012.

13. Machado S, Figueiredo N, Borges A, Pais M, Freitas L, Moura $\mathrm{P}$, et al. Acute kidney injury in pregnancy: a clinical challenge. J Nephrol. 2012;25:19-30. doi: 10.5301/ jn.5000013.

14. Sanders CL, Lucas MJ. Renal disease in pregnancy. Obstet Gynecol Clin North Am. 2001;28:593-600, vii. doi: 10.1016/S0889-8545(05)70220-5

15. AbdulkareemO A. Challenges in diagnosis and treatment of acute kidney injury during pregnancy. Nephrourol Mon. 2011;4:340-4. doi: 10.5812/kowsar.22517006.1608

16. Rahman S, Gupta RD, Islam N, Das A, Shaha AK, Khan MAI, et al. Pregnancy related acute renal failure in a tertiary care hospital in Bangladesh. J Med. 2012;13:12932. doi: 10.3329/jom.v13i2.12739.

17. Najar MS, Shah AR, Wani I, Reshi AR, Banday K, Bhat $\mathrm{MA}$, et al. Pregnancy related acute kidney injury: A single center experience from the Kashmir Valley. Indian J Nephrol. 2008;18:159-61. doi: 10.4103/0971-4065.45291

18. Ansari MR, Laghari MS, Solangi KB. Acute renal failure in pregnancy: one year observational study at Liaquat University Hospital, Hyderabad. J Pak Med Assoc. 2008;58:61-4.

19. Krane NK, Hamrahian M. Pregnancy: kidney diseases and hypertension. Am J kidney Dis. 2007;49:336-45. doi:10.1053/j.ajkd.2006.10.029

20. Kellum JA, Lameire N, Aspelin P, Barsoum RS, Burdmann EA, Goldstein SL, et al. Kidney disease: improving global outcomes (KDIGO) acute kidney injury work group. KDIGO clinical practice guideline for acute kidney injury. Kidney Int Suppl. 2012;2:1-138. doi: 10.1038/kisup.2012.1

21. Williams D, Davison J. Pregnancy Plus: Chronic kidney disease in pregnancy. BMJ. 2008;336:211-215. doi: 
10.1136/bmj.39406.652986.

22. Levey AS, Coresh J, Bolton K, Culleton B, Harvey KS, Ikizler TA, et al. K/DOQI clinical practice guidelines for chronic kidney disease: evaluation, classification, and stratification. Am J Kidney Dis. 2002;39:S1-266. doi: 10.1016/S0272-6386(02)70084-X.

23. Wang F, Xing T, Wang N, Huang Y. A clinical study of pregnancy-associated renal insufficiency. Kidney Blood Press Res. 2011;34:34-40. doi: 10.1159/000322117.

24. Teschan PE, Baxter CR, O'brien TF, Freyhof JN, Hall WH. Prophylactic hemodialysis in the treatment of acute renal failure. Ann Intern Med. 1960;53:992-1016.

25. Teschan PE, Baxter C, O'Brien T, Freyhof J, Hall W. Prophylactic hemodialysis in the treatment of acute renal failure. Annals of Internal Medicine, 53:992-1016, 1960. J Am Soc Nephrol. 1998;9:2384-97.

26. Tan PC, Tan NC, Omar SZ. Effect of high levels of human chorionic gonadotropin and estradiol on the severity of hyperemesis gravidarum. Clin Chem Lab Med. 2009;47:165-71. doi: 10.1515/CCLM.2009.041.

27. Oruç AS, Mert I, Akturk M, Aslan E, Polat B, Buyukkagnıcı $\mathrm{U}$, et al. Ghrelin and motilin levels in hyperemesis gravidarum. Arch Gynecol Obstet. 2013;287:1087-92. doi: 10.1007/s00404-012-2705-8.

28. Chiossi G, Neri I, Cavazzuti M, Basso G, Facchinetti F. Hyperemesis gravidarum complicated by Wernicke encephalopathy: background, case report, and review of the literature. Obstet Gynecol Surv. 2006;61:255-68. doi: 10.1097/01.ogx.0000206336.08794.65

29. Ismail SK, Kenny L. Review on hyperemesis gravidarum. Best Pract Res Clin Gastroenterol. 2007;21:755-69. doi:10.1016/j.bpg.2007.05.008

30. Bolin $\mathrm{M}$, Åkerud $\mathrm{H}$, Cnattingius S, Stephansson $\mathrm{O}$, Wikström A. Hyperemesis gravidarum and risks of placental dysfunction disorders: a population-based cohort study. Obstetric BJOG. 2013;120:541-7. doi: 10.1111/1471-0528.12132.

31. Johnson DR, Douglas D, Hauswald M, Tandberg D. Dehydration and orthostatic vital signs in women with hyperemesis gravidarum. Acad Emerg Med. 1995;2:6927. doi: 10.1111/j.1553-2712.1995.tb03620.x

32. Hill JB, Yost NP, Wendel Jr GD. Acute renal failure in association with severe hyperemesis gravidarum. Obstet Gynecol. 2002;100:1119-21.

33. Shim S-M, Ryu A-L, Kim Y-S. Acute Kidney Injury Arising from Severe Hyperemesis Gravidarum: Case Report with a Review of Literatures. Soonchunhyang Med Sci. 2015;21: 28-30. doi:10.15746/sms.15.007

34. Munib S, Khan SJ. Outcomes of pregnancy related acute renal failure. RMJ. 2008;33:189-92.

35. Chugh K, Singhal P, Sharma B, Pal Y, Mathew MT, Dhall $\mathrm{K}$, et al. Acute renal failure of obstetric origin. Obstet Gynecol. 1976;48:642-6.

36. Patel ML, Sachan R, Radheshyam PS. Acute renal failure in pregnancy: Tertiary centre experience from north Indian population. Nigerian medical journal: journal of the Nigeria Medical Association. Niger Med J. 2013;54:191-5. doi: 10.4103/0300-1652.114586.

37. Kumar KS, Krishna CR, Kumar VS. Pregnancy related acute renal failure. J Obstet Gynecol India. 2006;56:308-
10.

38. Altıntepe L, Gezginç K, Tonbul HZ, Çelik Ç, Güney I, Gezginç ST, et al. Etiology and prognosis in 36 acute renal failure cases related to pregnancy in central Anatolia. Eur J Gen Med. 2005;2:110-3. doi: 10.29333/ejgm/82320

39. Utaş C, Yalçındağ C, Taşkapan H, Güven M, Oymak $\mathrm{O}$, Yücesoy M. Acute renal failure in Central Anatolia. Nephrol Dial Transplant. 2000;15:152-5.

40. Krishna A, Singh R, Prasad N, Gupta A, Bhadauria D, Kaul A, et al. Maternal, fetal and renal outcomes of pregnancyassociated acute kidney injury requiring dialysis. Indian J Nephrol. 2015;25:77-81. doi: 10.4103/0971-4065.136890.

41. Williamson A. The premature separation of the normally implanted placenta. Am J Obstet Gynecol. 1922;3:385-99. doi: 10.1016/S0002-9378(22)90205-4

42. Redline RW, editor. The clinical implications of placental diagnoses. Seminars in perinatology. Elsevier; 2015.

43. Dambal A, Lakshmi K, Gorikhan G, MM U, ST K, MP M, et al. Obstetric acute kidney injury; a three year experience at a medical college hospital in north karnataka, India. J Clin Diagn Res. 2015;9:OC01-4. . doi: 10.7860/JCDR/2015/12897.5634.

44. Aishwarya A, Saraswathi K, Nirupa S. Mild Preeclampsia with abruptio Placenta and Acute Kidney Injury-A Case Report. RJPBCS. 2017;8:288-90.

45. Magee LA, Pels A, Helewa M, Rey E, von Dadelszen P. Diagnosis, evaluation, and management of the hypertensive disorders of pregnancy. J Obstet Gynaecol Can. 2014;36:575-576. doi: 10.1016/S17012163 (15)30533-8.

46. Schutte JM, Schuitemaker N, Van Roosmalen J, Steegers E. Substandard care in maternal mortality due to hypertensive disease in pregnancy in the Netherlands. BJOG. 2008;115;732-6. doi: 10.1111/j.14710528.2008.01702.x

47. Wilkinson H. Saving mothers' lives. Reviewing maternal deaths to make motherhood safer: 2006-2008. BJOG. 2011 Oct;118:1402-3. doi: 10.1111/j.1471-0528.2011.03097.x.

48. Mehrabadi A, Hutcheon JA, Lee L, Liston RM, Joseph K. Trends in postpartum hemorrhage from 2000 to 2009: a population-based study. BMC Pregnancy Childbirth. 2012;12:108. doi: 10.1186/1471-2393-12-108.

49. von Dadelszen P, Sawchuck D, McMaster R, Douglas MJ, Lee SK, Saunders S, et al. The active implementation of pregnancy hypertension guidelines in British Columbia. Obstet Gynecol. 2010;116:659-66. doi: 10.1097/ AOG.0b013e3181eb669d.

50. Magee LA, Helewa M, Moutquin J-M, Von Dadelszen P, Committee HG. Diagnosis, evaluation, and management of the hypertensive disorders of pregnancy. J Obstet Gynaecol Can. 2008;30:S1-48. doi: 10.1016/S17012163(15)30533-8.

51. Tuffnell D, Jankowicz D, Lindow S, Lyons G, Mason G, Russell I, et al. Outcomes of severe pre-eclampsia/ eclampsia in Yorkshire 1999/2003. BJOG. 2005;112:87580.

52. Singh R. Hypertensive disorders in pregnancy. Clinical Queries: Nephrology. 2013;2:47-55. doi:10.1016/j. cqn.2013.04.001

53. George JN. The association of pregnancy with thrombotic 
thrombocytopenic purpura-hemolytic uremic syndrome. Curr Opin Hematol. 2003;10;339-44.

54. Arrayhani M, El Youbi R, Sqalli T. Pregnancy-related acute kidney injury: experience of the nephrology unit at the university hospital of fez, Morocco. ISRN Nephrol. 2012;2013:109034. doi: 10.5402/2013/109034.

55. Mehrabadi A, Liu S, Bartholomew S, Hutcheon JA, Magee LA, Kramer MS, et al. Hypertensive disorders of pregnancy and the recent increase in obstetric acute renal failure in Canada: population based retrospective cohort study. BMJ. 2014;349:g4731. doi: 10.1136/bmj.g4731.

56. Bentata Y, Housni B, Mimouni A, Azzouzi A, Abouqal R. Acute kidney injury related to pregnancy in developing countries: etiology and risk factors in an intensive care unit. J Nephrol. 2012;25:764-75. doi: 10.5301/jn.5000058.

57. Benedetto C, Zonca M, Marozio L, Dolci C, Carandente F, Massobrio M. Blood pressure patterns in normal pregnancy and in pregnancy-induced hypertension, preeclampsia, and chronic hypertension. Obstet Gynecol. 1996;88:503-10. doi:10.1016/0029-7844(96)00217-7

58. Huang $\mathrm{C}$, Chen S. Acute kidney injury during pregnancy and puerperium: a retrospective study in a single center. BMC Nephrol.2017;18:146. doi: 10.1186/s12882-0170551-4.

Copyright (C) 2018 The Author(s); Published by Nickan Research Institute. This is an open-access article distributed under the terms of the Creative Commons Attribution License (http://creativecommons.org/licenses/by/4.0), which permits unrestricted use, distribution, and reproduction in any medium, provided the original work is properly cited. 